\title{
Bioreactor systems are essentially required for stem cell bioprocessing
}

\author{
Jae Min Cha ${ }^{1}$, Min-Young Lee ${ }^{2}$, Jongin Hong ${ }^{3}$ \\ ${ }^{1} 3$ D Stem Cell Bioprocessing Laboratory, Department of Mechatronics, Incheon National University, Incheon, Korea \\ ${ }^{2}$ Smart Healthcare \& Device Research Center, Research Institute for Future Medicine, Samsung Medical Center, Sungkyunkwan \\ University School of Medicine, Seoul, Korea \\ ${ }^{3}$ Department of Chemistry, Chung-Ang University, Seoul, Korea
}

Received: September 19, 2018

Revised: October 14, 2018

Accepted: October 16, 2018

Corresponding author:

Jae Min Cha

3D Stem Cell Bioprocessing

Laboratory, Department of

Mechatronics, Incheon National

University, 119 Academy-ro,

Yeonsu-gu, Incheon 22012,

Korea

Tel: +82-32-835-8686

E-mail: j.cha@inu.ac.kr

\begin{abstract}
As stem cell technologies have rapidly advanced, the stem cell therapy market has been forecast to reach hundreds of millions of USD in market value within the next 5 years. Regulatory frameworks throughout the stem cell market have been concurrently established, which will encourage the advent of a variety of stem cell products in our society. Given the circumstances, stem cell bioprocessing has emerged as one of the most critical fields of research to address a number of issues that currently exist in manufacturing clinical-grade stem cells at an industrial scale. Highly specialized bioreactor designs are at the center of essentially required technologies in the field of stem cell bioprocessing, which ultimately aim for automated, standardized, traceable, cost-effective, safe, and regulatory-compliant manufacture of stem cell-based products. In this review, recently developed bioreactor designs to introduce important regulatory factors to three-dimensional stem cell culture are exemplified, and prerequisites for the ideal bioreactor systems for stem cell bioprocessing are discussed.
\end{abstract}

Keywords: Bioreactors; Cell culture techniques; Clinical grade stem cells; Industrial scale; Stem cell bioprocessing

\section{INTRODUCTION}

As stem cell research has rapidly advanced and gained much interest in recent years, the public is now well aware of this research field and the huge potential of stem cells in therapeutics. The successful manufacture of medicinal products based on stem cells and their derivatives is crucially required to extend the benefits of therapeutic solutions provided by stem cells through our society. Stem cell bioprocessing is a very important step in the translation of various scientific breakthroughs developed in the laboratory to the bedside. A variety of principles and practices in engineering and cell biology are involved in stem cell bioprocessing for the realization of large-scale, automated manufacturing processes for stem cell-based medicinal products. The development of bioreactor systems with the ability to precisely control and recapitulate stem cell niche factors is essential to achieve stem cell expansion and controlled dif-
This is an Open Access article distributed under the terms of the Creative Commons Attribution Non-Commercial License (http:// creativecommons.org/licenses/ by-nc/4.0/). 
ferentiation in large-scale bioprocessing. In this review, recent bioreactor technologies for three-dimensional (3D) stem cell culture are introduced. These technologies were specially designed to provide mimicry of in situ stem cell microenvironments including oxygen levels and physiological mechanical forces, and the need for continuous processing features in a bioreactor system is discussed.

\section{CONTROLLING OXYGEN LEVELS IN BIO- REACTOR SYSTEMS}

Oxygen largely participates in cellular metabolism and is an important microenvironmental factor in the determination of stem cell fate. Reduced oxygen tension in culture that mimics in vivo physiological situations can maintain stem cells at a primitive stage as well as contribute to regulating lineage-specific differentiation. Human mesenchymal stem cells (MSCs) grown in low-oxygen condition (hypoxia, $1 \%$ to $5 \% \mathrm{O}_{2}$ ) displayed higher colony-forming activity and greater expression of various genes related to the innate characteristics of stem cells than those cultured in normal oxygen condition (normoxia, $10 \%$ to $21 \% \mathrm{O}_{2}$ ) [1]. Kasper's research group reported that hypoxic culture conditions improved the self-renewal capacity of human MSCs, which maintained their differentiation potential, and various cytokines expressed by human MSCs under hypoxia appeared to be directly related to the improved proliferation and differentiation capacities [2,3]. These results were noteworthy as such oxygen-dependent expression of a particular set of cytokines in hypoxic MSC culture played a decisive role in enhancing the growth potential of undifferentiated MSCs. Likewise, it was also reported that culture conditions of $5 \% \mathrm{O}_{2}$ resulted in reduced frequency of spontaneous differentiation of human embryonic stem cells (ESCS) through the up-regulation of hypoxia-inducible factors [4]. As a number of previous studies have reported, bioreactors enable the exquisite control of oxygen levels at various scales that cannot be readily achieved by conventional static culture methods. Lovett et al. [5] developed a modular bioreactor that could generate well-differentiated oxygen gradients and demonstrated that chondrogenesis of human MSCs was significantly enhanced at hypoxic levels of oxygen, whereas adipogenesis mostly took place in culture conditions with $20 \% \mathrm{O}_{2}$. Similarly, sizecontrolled embryoid bodies (EBs) derived from human ESCs were cultured in an $\mathrm{O}_{2}$-controlled spinner bioreactor. Compared to a normoxic environment, $4 \% \mathrm{O}_{2}$ caused the up-regulation of cardiac genes [6]. In addition, Wu et al. [7] cultured mouse and human ESCs using a stirred-suspension bioreactor with adjustable oxygen levels. They demonstrated different behaviors between mouse and human ESCs under hypoxic conditions and successfully aligned their experimental results with a mathematical model. This framework was meaningful since such validated mathematical modeling could facilitate extended bioprocess designs for the production of stem cell therapeutics [7].

\section{APPLYING PHYSIOLOGICAL MECHANI- CAL FORCES USING BIOREACTOR SYS- TEMS}

Conventional cell culture systems often disregard the mechanical stimuli that significantly influence the intricate in vivo cellular microenvironments. It is well understood that specific mechanical forces with given magnitudes regulate tissue development and remodeling of bone, cartilage, muscle, and cardiovascular tissues. Extracellular matrices could be readily influenced by various extracellular mechanical stresses and thus, the cell surface could be directly changed by deforming integrin-binding sites. The resulting mechanobiological responses are critically dependent on the type of mechanical stress and the location at which mechanical loading takes place [8]. Cellular differentiation pathways could be affected by such mechanical forces, which have been widely applied for the control of tissue morphogenesis from stem cells [9]. For instance, primarily cultured myofibroblasts were seeded in 3D porous polyurethane scaffolds and subsequently cultured in a bioreactor with the application of cyclic mechanical stretching, resulting in effective differentiation into smooth muscle cells with a consistent cellular alignment $[10,11]$. Articular cartilage is most frequently subjected to deformational loading and hydrostatic pressure. Therefore, a specialized bioreactor implemented with such mechanical conditions in the cellular microenvironment was developed to engineer artificial cartilage [12]. In addition, other studies demonstrated that bone morphogenesis was successfully accelerated by applying longitudinal strain to MSC culture [13]. A biaxial rotating bioreactor was also designed for bone tissue engineering and achieved higher cellularity, confluence, and robust osteogenic differentiation of MSCs compared to other types of bioreactors such as spinner-type, perfusion, and rotating wall vessel bioreactors $[14,15]$. Another advanced bioreactor combining dynamic tension and torsion was developed to more sophisticatedly mimic in situ physical microenvironments of liga- 
ments and resulted in significant improvement in the function of engineered human ligament tissues $[16,17]$. An interesting study using a mechanical compression bioreactor demonstrated that hydrogel-encapsulated MSCs experiencing compression stress up-regulated chondrogenic genes in the absence of transforming growth factor $\beta 1$ (TGF- $\beta 1$ ), whereas human EB-derived mesenchymal progenitor cells were highly dependent on the supplementation of TGF- $\beta 1$ for similar outcomes [18]. Taken together, the aforementioned bioreactors with novel designs to recreate physiological loading environments not only contributed to a better understanding of stem cell behaviors in their specific microenvironments, but also suggested promising strategies to manufacture functional tissue-engineered products.

\section{CONTROLLING FLOW SHEAR STRESS IN BIOREACTOR SYSTEMS}

It is well recognized that the vascular endothelium is regularly subjected to hemodynamic forces of blood vessels in vivo. Therefore, different levels of shear stress influence the functional properties of vascular endothelial and smooth muscle cells. A bioreactor simulating blood flow was designed to provide human induced pluripotent stem cell-derived endothelial cells (hiPSC-ECs) with biomimetic shear stress [19]. The biomimetic flow bioreactor efficiently matured hiPSC-ECs into arterial-like cells in 24 hours, which was not achieved by traditional exogenous addition of soluble factors to the cell culture. In addition, a bioreactor that mimicked in vivo mechanical loading environments of vascular tissues was developed to induce differentiation of human MSCs into vascular cells [20]. MSCs seeded on double-layered tubular scaffolds were subjected to shear stress $\left(2.5 \mathrm{dyne} / \mathrm{cm}^{2}\right)$ and cyclic circumferential stretching generated by pulsatile flow in the bioreactor system. Consequently, MSCs were efficiently differentiated into ECs. Flow shear stress could also be generated by perfusion-based or agitation-based bioreactors. In general, direct perfusion has been reported to be beneficial for stem cells by increasing their cellularity and matrix synthesis in the engineered tissue architecture, while providing better control of nutrient and oxygen delivery to the deeper parts of the cultured tissue [21-23]. However, while high levels of shear stress serve the purpose of engineering vascular endothelium tissues, they could generate turbulent eddies that interact with the cell surface, which could lead to unrecoverable cellular damages due to the high rate of local energy dissipation $[24,25]$. Therefore, when us- ing the spinner flask-type bioreactors, an optimal impeller speed range must be determined to culture stem cells within conditions that allow for minimal hydrodynamic shear stress generation.

\section{CONTINUOUS PROCESSING OF BIORE- ACTOR}

Continuous processing requires procedures to be operated with culture medium that can be continually processed into intermediate or final stem cell products by controlled flow in and out of a bioreactor. Continuous processing is highly advantageous to achieve control, reproducibility, validation, and safety of the bioprocesses and manufactured stem cell products. It facilitates automation and requires less human intervention, contrasting fed-batch production that entirely relies on an isolated volume in a single manufacture cycle. Yeo et al. [26] investigated the impact of metabolic stress caused by inefficient feeding of fed-batch-type bioreactor systems, as demonstrated by experimental data showing good agreement with mathematical modeling. They reported that although sufficient nutrients and growth factors were provided to culture in a given culture time, unscheduled differentiation and reduced proliferation of murine ESCs took place because of the accumulation of inhibitory metabolites such as lactate and ammonia. In contrast, continuous medium perfusion in a bioreactor efficiently circumvented metabolic by-product accumulation and maintained it below critically toxic levels, resulting in the robust expansion of ESCs with high pluripotency. In addition, Lambrechts et al. [27] developed a hollow-fiber perfusion bioreactor (HFPB) that enabled real-time monitoring of culture parameters during the bioprocessing operation. The HFPB successfully achieved clinical-scale production of human periosteum-derived stem cells, and the function of tracking the intermediate process performances could aid in dealing with variations resulting from donor-to-donor batches, such as different needs for nutrient and optimal timing for harvesting cells.

\section{CONCLUSION}

Unlike the well-established manufacturing fields of therapeutic antibodies or virus vaccines, bioprocessing of highly complex and susceptible stem cells involves controlling a broader spectrum of parameters. Meanwhile, the fundamental requirements for clinical approval, such as therapeutic potency, purity, stability, efficacy, safety, and quality, are yet 
to be considered. A scalable and robust bioreactor system that provides controlled physiochemical culture environments for stem cells along with efficient monitoring modules for read-out of informative culture parameters represents a key element for stem cell biomanufacturing technologies. As exemplified in this review, although limited, numerous bioreactor systems with flexible culture strategies have been designed to date, and further investigations are actively ongoing in the field. We believe that priceless knowledge that is continuously accumulating by such endeavor will enable the realization of validated, streamlined 3D stem cell bioprocesses, which will ultimately contribute to the manufacture of clinically and commercially viable stem cell-based medicinal products.

\section{CONFLICTS OF INTEREST}

No potential conflict of interest relevant to this article was reported.

\section{ACKNOWLEDGMENTS}

This research was supported by the National Research Foundation of Korea (NRF) funded by the Ministry of Science \& ICT (NRF2017R1C1B2002624), and a research grant (2018ER610300) by the Research of Korea Centers for Disease Control and Prevention.

\section{ORCID}

Jae Min Cha https://orcid.org/0000-0002-8713-2078

Min-Young Lee https://orcid.org/0000-0003-3396-7632

Jongin Hong https://orcid.org/0000-0002-2891-5785

\section{REFERENCES}

1. Grayson WL, Zhao F, Izadpanah R, Bunnell B, Ma T. Effects of hypoxia on human mesenchymal stem cell expansion and plasticity in 3D constructs. J Cell Physiol 2006;207:3319.

2. Lavrentieva A, Majore I, Kasper C, Hass R. Effects of hypoxic culture conditions on umbilical cord-derived human mesenchymal stem cells. Cell Commun Signal 2010;8:18.

3. Lonne M, Lavrentieva A, Walter JG, Kasper C. Analysis of oxygen-dependent cytokine expression in human mesenchymal stem cells derived from umbilical cord. Cell Tissue Res 2013;353:117-22.

4. Forristal CE, Wright KL, Hanley NA, Oreffo RO, Houghton
FD. Hypoxia inducible factors regulate pluripotency and proliferation in human embryonic stem cells cultured at reduced oxygen tensions. Reproduction 2010;139:85-97.

5. Lovett M, Rockwood D, Baryshyan A, Kaplan DL. Simple modular bioreactors for tissue engineering: a system for characterization of oxygen gradients, human mesenchymal stem cell differentiation, and prevascularization. Tissue Eng Part C Methods 2010;16:1565-73.

6. Niebruegge S, Bauwens CL, Peerani R, Thavandiran N, Masse $\mathrm{S}$, Sevaptisidis E, et al. Generation of human embryonic stem cell-derived mesoderm and cardiac cells using size-specified aggregates in an oxygen-controlled bioreactor. Biotechnol Bioeng 2009;102:493-507.

7. Wu J, Rostami MR, Cadavid Olaya DP, Tzanakakis ES. Oxygen transport and stem cell aggregation in stirred-suspension bioreactor cultures. PLoS One 2014;9:e102486.

8. Placzek MR, Chung IM, Macedo HM, Ismail S, Mortera Blanco T, Lim M, et al. Stem cell bioprocessing: fundamentals and principles. J R Soc Interface 2009;6:209-32.

9. Patwari P, Lee RT. Mechanical control of tissue morphogenesis. Circ Res 2008;103:234-43.

10. Cha JM, Park SN, Park GO, Kim JK, Suh H. Construction of functional soft tissues from premodulated smooth muscle cells using a bioreactor system. Artif Organs 2006;30:7047.

11. Cha JM, Park SN, Noh SH, Suh H. Time-dependent modulation of alignment and differentiation of smooth muscle cells seeded on a porous substrate undergoing cyclic mechanical strain. Artif Organs 2006;30:250-8.

12. Hung CT, Mauck RL, Wang CC, Lima EG, Ateshian GA. A paradigm for functional tissue engineering of articular cartilage via applied physiologic deformational loading. Ann Biomed Eng 2004;32:35-49.

13. van Griensven M, Diederichs S, Roeker S, Boehm S, Peterbauer A, Wolbank S, et al. Mechanical strain using 2D and 3D bioreactors induces osteogenesis: implications for bone tissue engineering. Adv Biochem Eng Biotechnol 2009;112:95-123.

14. Zhang ZY, Teoh SH, Teo EY, Khoon Chong MS, Shin CW, Tien FT, et al. A comparison of bioreactors for culture of fetal mesenchymal stem cells for bone tissue engineering. Biomaterials 2010;31:8684-95.

15. Zhang ZY, Teoh SH, Chong WS, Foo TT, Chng YC, Choolani $\mathrm{M}$, et al. A biaxial rotating bioreactor for the culture of fetal mesenchymal stem cells for bone tissue engineering. Biomaterials 2009;30:2694-704.

16. Breidenbach AP, Gilday SD, Lalley AL, Dyment NA, Gooch 
C, Shearn JT, et al. Functional tissue engineering of tendon: establishing biological success criteria for improving tendon repair. J Biomech 2014;47:1941-8.

17. Butler DL, Juncosa-Melvin N, Boivin GP, Galloway MT, Shearn JT, Gooch C, et al. Functional tissue engineering for tendon repair: a multidisciplinary strategy using mesenchymal stem cells, bioscaffolds, and mechanical stimulation. J Orthop Res 2008;26:1-9.

18. Terraciano V, Hwang N, Moroni L, Park HB, Zhang Z, Mizrahi J, et al. Differential response of adult and embryonic mesenchymal progenitor cells to mechanical compression in hydrogels. Stem Cells 2007;25:2730-8.

19. Sivarapatna A, Ghaedi M, Le AV, Mendez JJ, Qyang Y, Niklason LE. Arterial specification of endothelial cells derived from human induced pluripotent stem cells in a biomimetic flow bioreactor. Biomaterials 2015;53:621-33.

20. Kim DH, Heo SJ, Kang YG, Shin JW, Park SH, Shin JW. Shear stress and circumferential stretch by pulsatile flow direct vascular endothelial lineage commitment of mesenchymal stem cells in engineered blood vessels. J Mater Sci Mater Med 2016;27:60.

21. Carrier RL, Rupnick M, Langer R, Schoen FJ, Freed LE, Vunjak-Novakovic G. Perfusion improves tissue architecture of engineered cardiac muscle. Tissue Eng 2002;8:175-88.

22. Davisson T, Sah RL, Ratcliffe A. Perfusion increases cell content and matrix synthesis in chondrocyte three-dimensional cultures. Tissue Eng 2002;8:807-16.

23. Tigli RS, Cannizaro C, Gumusderelioglu M, Kaplan DL. Chondrogenesis in perfusion bioreactors using porous silk scaffolds and hESC-derived MSCs. J Biomed Mater Res A 2011;96:21-8.

24. Croughan MS, Sayre ES, Wang DI. Viscous reduction of turbulent damage in animal cell culture. Biotechnol Bioeng 1989;33:862-72.

25. King JA, Miller WM. Bioreactor development for stem cell expansion and controlled differentiation. Curr Opin Chem Biol 2007;11:394-8.

26. Yeo D, Kiparissides A, Cha JM, Aguilar-Gallardo C, Polak JM, Tsiridis E, et al. Improving embryonic stem cell expansion through the combination of perfusion and Bioprocess model design. PLoS One 2013;8:e81728.

27. Lambrechts T, Papantoniou I, Rice B, Schrooten J, Luyten FP, Aerts JM. Large-scale progenitor cell expansion for multiple donors in a monitored hollow fibre bioreactor. Cytotherapy 2016;18:1219-33. 